\title{
Rhythm histograms and musical meter: A corpus study of Malian percussion music
}

\author{
Justin London $^{1} \cdot$ Rainer Polak $^{2} \cdot$ Nori Jacoby $^{3}$
}

Published online: 6 July 2016

(C) Psychonomic Society, Inc. 2016

\begin{abstract}
Studies of musical corpora have given empirical grounding to the various features that characterize particular musical styles and genres. Palmer \& Krumhansl (1990) found that in Western classical music the likeliest places for a note to occur are the most strongly accented beats in a measure, and this was also found in subsequent studies using both Western classical and folk music corpora (Huron \& Ommen, 2006; Temperley, 2010). We present a rhythmic analysis of a corpus of 15 performances of percussion music from Bamako, Mali. In our corpus, the relative frequency of note onsets in a given metrical position does not correspond to patterns of metrical accent, though there is a stable relationship between onset frequency and metrical position. The implications of this non-congruence between simple statistical likelihood and metrical structure for the ways in which meter and metrical accent may be learned and understood are discussed, along with importance of cross-cultural studies for psychological research.
\end{abstract}

Keywords Musical rhythm · Cross-cultural study · Situated cognition

Justin London

jlondon@carleton.edu

1 Carleton College, Music, 1 North College Street, Northfield, MN 55057, USA

2 Hochschule für Musik und Tanz Köln, Unter Krahnenbäumen 87, 50668 Cologne, Germany

3 Massachusetts Institute of Technology, Cambridge, MA 02139, USA

\section{Introduction and background}

One of the most famous rhythms in rock and roll is the "Bo Diddley Beat." It is a five note syncopated pattern with the durational proportions $3: 3: 4: 2: 4$, and it is derived from the son clave rhythm common in the music of the African diaspora (Chor, 2010; Stover, 2012; see Fig. 1). When we hear the Bo Diddley rhythm we do more than simply grasp these proportions; we also relate them to a particular meter. Meters are endogenous, dynamic timing frameworks for the perception of rhythmic patterns and for sensorimotor synchronization and action (Large, 2008; London, 2012). Meters involve multiple, coordinated periodicities, whose alignment gives rise to different degrees of accent (Lerdahl \& Jackendoff, 1983; Large \& Palmer, 2002; Temperley, 2010). The rows of dots in Fig. 1 indicate the various metric periodicities present in the "4/4" meter under which the Bo Diddley rhythm is produced and understood. Columns of dots indicate the location of the beats, and column height is indicative of their relative degrees of metric accent. Only the first and last notes in each measure align with any columns of dots (i.e., are "on the beat"). Indeed, the Bo Diddley pattern is "syncopated" precisely because it contains three successive notes that are articulated off the beat.

A recent thread of musical rhythm research has examined patterns of note onsets relative to their metric contexts in various musical corpora. In so far as the observed onset distribution is from a representative sample, it then may be regarded as a model of the metrical likelihood for the occurrence of rhythmic events in that particular repertoire. Palmer \& Krumhansl (1990), using an ad hoc corpus of classical keyboard music (Bach, Mozart, Brahms, and Shostakovich), found a strong correlation between onset frequencies and patterns of accent characteristic of 


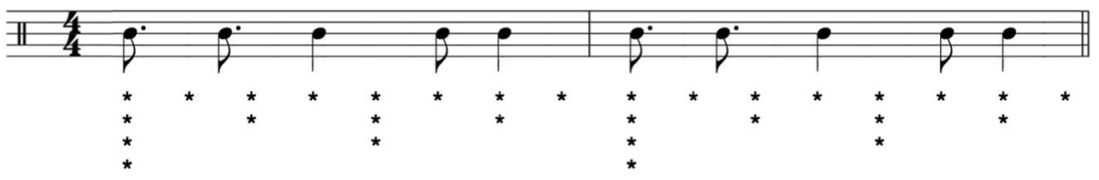

Fig. 1 The "Bo Diddley"/Son Clave rhythmic figure, with metrical analysis after Lerdahl \& Jackendoff (1983)

meters often found in Western music (see Fig. 2). Huron \& Ommen (2006) examined a larger corpus of 1537 songs from the Essen Folksong Collection and found a similarly robust correlation. In these two studies, metrical likelihood was correlated with "on-beatness," and thus it was proposed that this might engender the acquisition of metrical knowledge via a statistical learning process:

It is unlikely that mental representations for meter are learned through formal training; very few of the listeners in these experiments had had exposure to music theory. Rather, the rhythmic organization of temporal patterns appears to be instantiated in the frequency with which events occur in various metrical positions in Western tonal music and affects [their] perceived relatedness and memory strength (Palmer \& Krumhansl, 1990, p. 739).

Holzapfel (2015) examined the distribution of rhythmic onsets in a corpus of 913 notated compositions of Turkish modal art music, characterized by particular melodic rules (makam) and rhythmic modes (usul). Although intended to establish temporal frameworks, usul are not pulse- based meters, but basic drum stroke patterns; in this respect, they are analogs to the "Bo Diddley" rhythm noted above. Holzapfel found strong correspondences between the six usul used in his corpus and the frequency of melodic (vocal) onsets in their representative pieces (see Fig. 3).

Two important points are evident in Fig. 3. The first is that shapes of these histograms do not correspond to patterns of metrical accent as per Turkish music-theoretic descriptions of each usul (Holzapfel 2015, p. 7). Second, while there is a strong correspondence between note probability and the usul stroke patterns, in some pieces other onset locations are also prominent (e.g., Sofyan, Türk Aksaği). The correspondences between $u s u l$ and onset position are thus weaker than those found between metric position and onset position in corpuses of Western music, which led Holzapfel to conclude that in comparison to Western music, meter in Turkish music is less stratified (Holzapfel, 2015, p. 24).

Africanist musicology has long noted that rhythms in African music can be anchored to the underlying meter in less predictable, more contingent ways, particularly by affording anti-phase (off-beat) and other, more complex
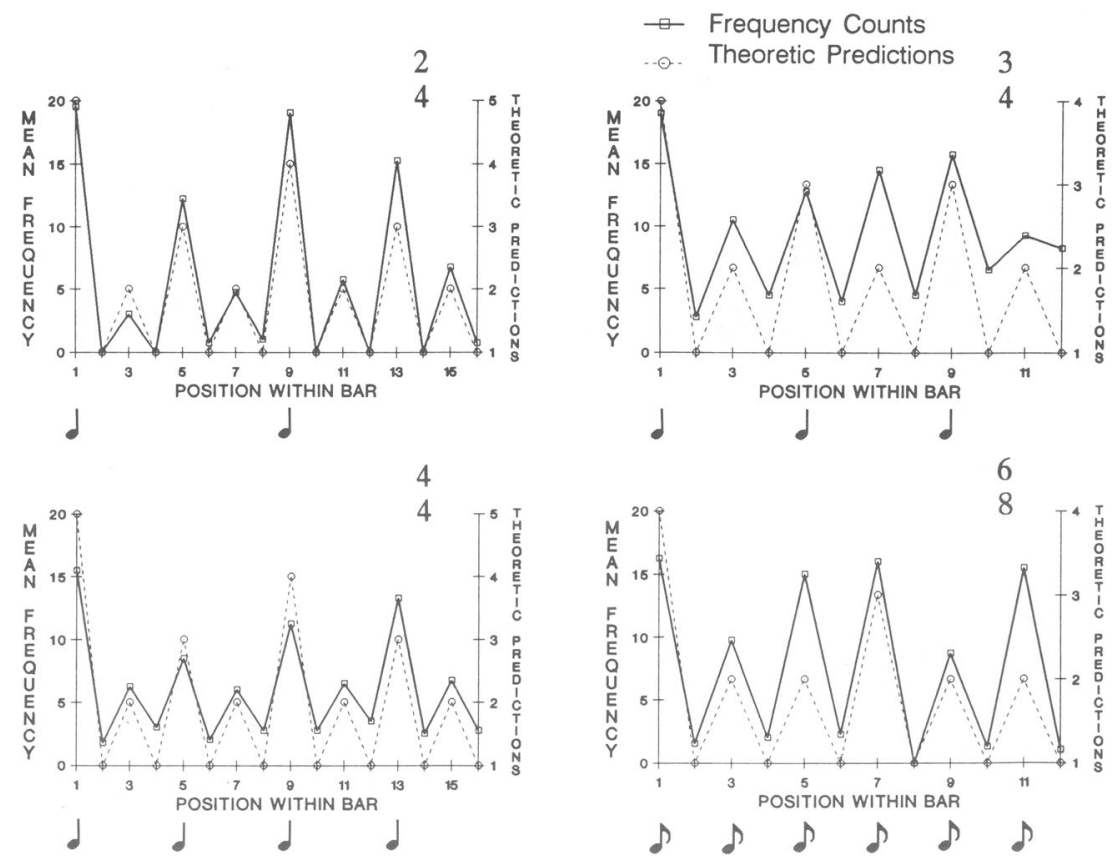

Fig. 2 a-d Onset frequencies relative to metrical position in Palmer \& Krumhansl (1990) corpus of classical keyboard music. a 2/4 meter, b 3/4 meter, c $4 / 4$ meter, and $\mathbf{d} 6 / 8$ meter 


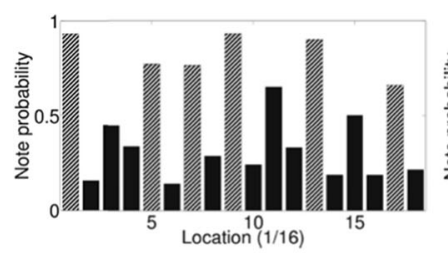

(a) Aksak

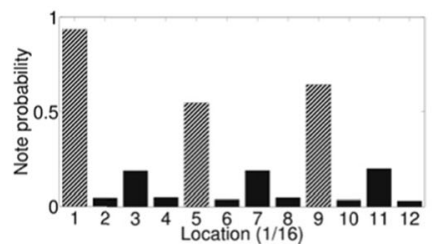

(d) Semai

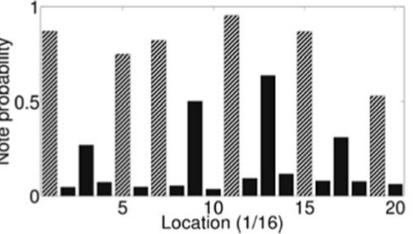

(b) Curcuna

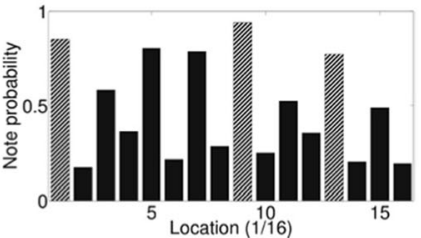

(e) Sofyan

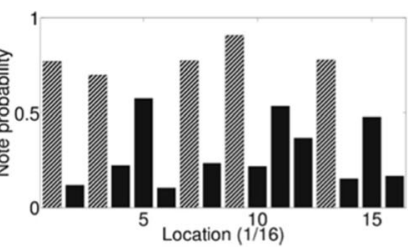

(c) Düyek

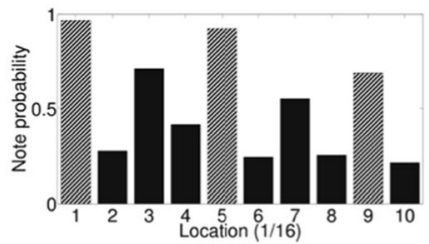

(f) Türk Aksaği
Fig. 3 Onset frequencies relative to metric position in Holzapfel (2015) corpus of Turkish makam music, divided according to six usul. Onsets are given irrespective of note duration. Probabilities of note occurrence are

types of non-congruent rhythm-meter-relationships (Kolinski, 1973; Locke, 1998, 2010; Kubik, 1988; Arom, 1991; Agawu, 2006; Burns, 2010) Indeed, a repertoire in which a significant portion of note onsets tend to be non-congruent with the metrical framework is Kolinski's (1973) very notion of a "contrametric" style of rhythmic organization. Contrametric rhythm is particularly characteristic of much sub-Saharan rhythm (see Locke, 1982; Arom, 1991). Yet the underlying meters to which sub-Saharan rhythms are anchored are, in most cases, the same meters found as in Western music. The most common meters involve a cycle of four even beats that are subdivided into two, three, or four more rapid subdivisions. ${ }^{1}$

Here we present data from a corpus of Malian drum ensemble performances; like Holzapfel, our corpus is characterized by contrametric rhythms. In addition to expanding the cultural and stylistic range of rhythmic analysis, our study furthers the aims of corpus studies of musical rhythm and meter in two ways. First, the statistical analyses we present are derived from the timings of complete actual performances, rather than from score-based symbolic representations. Second, our data include all parts of the musical texture, rather than the melody alone. This gives us a richer and more ecologically valid picture of the context in which listeners might acquire rhythmic knowledge. Moreover, by

\footnotetext{
${ }^{1}$ Meter in African music, and especially how to notate/represent it, has been a contentious topic in the ethnomusicological literature. However, a strong consensus has emerged that while the rhythms found in various West African musical styles are characteristically different from those found in many Western musical styles, their basic metric frameworks are not; this is based both on the testimony of African musicians and dancers as well as music analysis (Locke, 1982, 1992, 1998; Nzewi, 1997; Anku, 2000; Agawu, 2006; Burns, 2010; Polak, 2010).
}

given on the ordinate metric positions on the abcissa are in sixteenth notes. The grey shaded bars in each panel mark metric positions that correspond to the the $u s u l$ drumstroke pattern

including the complete musical texture and by giving a broader situated account of how these pieces are heard, we suggest how mental representations for meter in characteristically contrametic styles may be developed.

\section{Method}

\section{Ensemble and repertoire}

Malian jembe drum ensemble music is the musical component to larger, often participatory social events that involve dancing, eulogy, masquerade or puppetry, and other modes of social interactions (Polak, 2007). The percussion ensembles typically involve three distinct musical roles: a variative lead drum, a timeline or "hook" drum that plays the characteristic asymmetrical rhythmic figure that identifies each particular piece, and one or more ostinato accompaniment parts that maintain the basic beat. These roles are assigned to specific instruments in the ensemble (Polak, 2010). The lead part is played on the first jembe, a goblet shaped drum played with the percussionist's bare hands. The hook part is played on the dundun, a cylindrical drum beaten with a stick. The accompaniment part is played by a second jembe. Metrical structure in Malian drum ensemble music most often involves an isochronous 4-beat cycle, or multiples of it such as an 8-beat cycle. In our corpus, the subdivision is always ternary; in Western music it would be analogous to $12 / 8$ meter. In addition, many pieces of Malian drum music, including all of the pieces analyzed here, involve a gradual increase in speed over the course of an entire performance.

Our corpus is comprised of three different pieces, "Manjanin," "Maraka," and "Woloso," which are part of 
the core repertoire of standard pieces in the urban tradition of Bamako, the Malian capital (Polak, 2012).

\section{Data collection}

In 2006/2007, R.P. collected a set of multi-track and video recordings of 15 complete live drum performances in Bamako, Mali. Unidirectional microphones (AKG C-419) clipped to the drum rims recorded uncompressed audio to a mobile digital four-track studio (Edirol R4). Recording sessions took place open-air, where there was little acoustical crosstalk of instruments and reverberation from walls. Sony Vegas Proversions 11 and 12 (http://www. sonycreativesoftware.com) was used for audio synchronizing, archiving, and editing; Sony Soundforge Pro (ver. 10) and Steinberg Wavelab (ver. 7; http://www.steinberg. net) were used for audio editing and automatic onset (attack point) detection. Onset markers were checked by eye and then onset timings were converted into a text file and imported into Microsoft Excel (Microsoft, Redmond, WA) for formatting and cleanup.

The 15 recorded performances yielded some $50 \mathrm{~min}$ of audio recording, i.e., 42,297 onsets/data points. Approximately $5.6 \%(\approx 2400$ onsets) were removed from the data set, either (1) in trimming beginning and ending events, where all parts were not yet present and/or the basic pulse and rhythm had not been established (1186 events); or (2) in removing sub-metrical ornaments, such as rolls and flams, filtered via a binning procedure. The histogram at the bottom of Fig. 4 also shows the distribution of all events in the piece relative to the metrical cycle. Despite a significant longterm tempo change (from 120 to $180 \mathrm{bpm}$, on average) the musicians maintain these highly stable onset positions over the entire performance; similar stability was found in all 15 recordings in the corpus.

\section{Results}

Figure 5 gives event distribution histograms, binned according to their positions relative to the metric grid, for each of the three pieces in our corpus. The decimal figures on the $x$-axis indicate the average position of each subdivision articulation within each beat, derived from the actual timing performances and normalized for tempo changes relative to the local 4-beat measure. From these timing positions, one can also deduce the periodicity of the beat, as the uneven timing of the three subdivisions displays a periodically recurring pattern. For example, in Manjanin the subdivisions are positioned at about $25 \%$ and $60 \%$ of the beat duration (see Fig. 5).

Over the course of the entire metric cycle the positions which articulate the hook rhythms (marked with asterisks) are among the most frequently articulated positions in each histogram. Apart from the downbeat $(1.0=$ start/end-point of metric cycle), onbeat positions (2.0,3.0, or 4.0) are articulated less frequently than the upbeat metrical positions that immediately precede them, save for the $3 \mathrm{rd}$ and 4 th beat positions in Maraka. Mid-beat positions are articulated much less frequently than the surrounding positions. Even more significant is the fact that the most frequent onset locations in each histogram are not periodically spaced (e.g., if one uses the four or five most frequent onset locations as points of reference, Manjanin and Woloso exhibit a $2+3+3+4$ spacing, while Maraka exhibits a $2+4+3+2+1$ pattern), while the underlying metric beats are periodic. Thus, while at least three levels of rhythmic hierarchy seem clearly evident based on

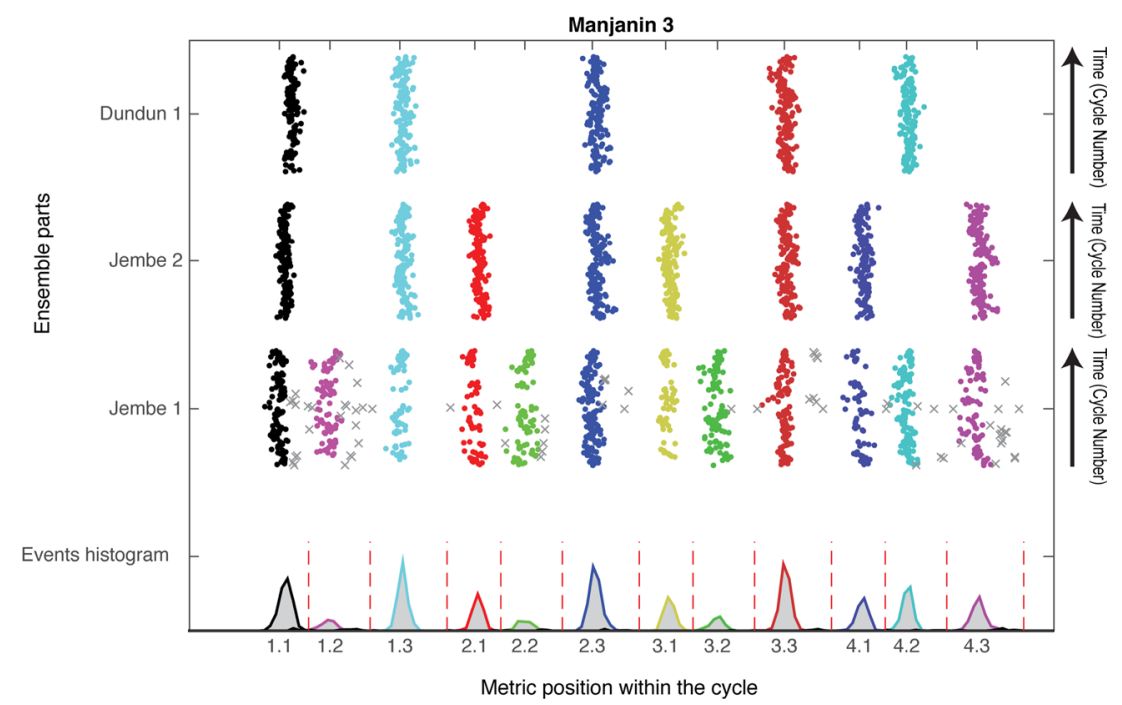

Fig. 4 Sample display of all data points (2893 onsets) from one recording in our corpus, a three-part performance of the piece "Manjanin." Filtered onsets are marked in gray. The lower part of the panel shows onset timing histograms of all events in the piece (with bin size of $1 \%$ of the metric cycle). Dashed lines show heuristic borders between the clusters 

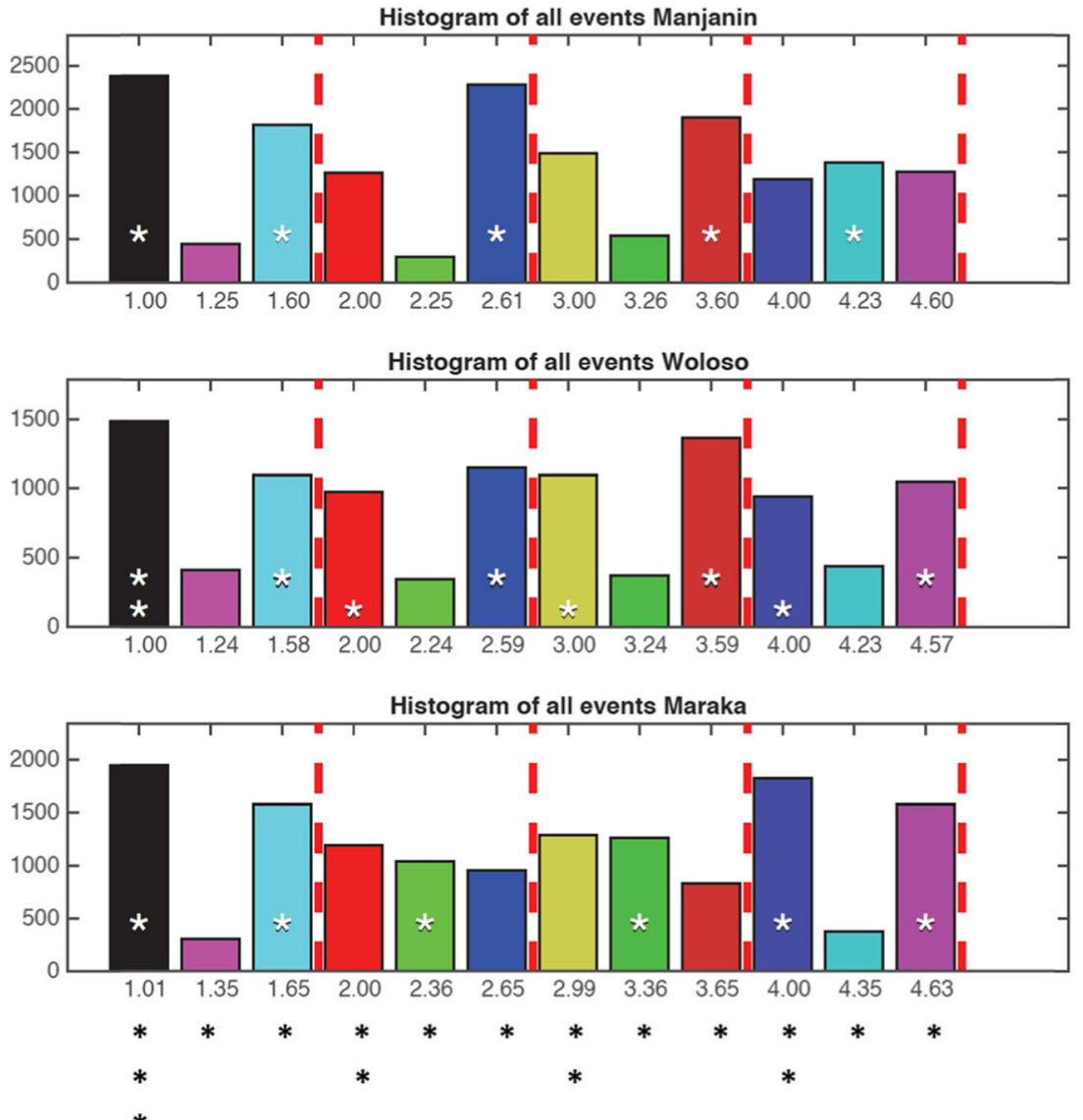

Fig. 5 Onset frequencies relative to metric position, separated by piece, in the Malian percussion corpus: a Manjanin, b Woloso, and c Maraka. Onsets that correspond to the "hook" pattern are marked with asterisks within the histogram (Woloso's 8-beat hook pattern is marked with two rows of asterisks). Red dashed lines indicate ternary subdivision groups in each panel; the metric grid for all three pieces is indicated by the asterisks beneath the bottom panel (Maraka)

meter finding algorithms used in music information retrieval contexts (Jehan, 2005; Ellis, 2007; Tomic \& Janata, 2008; Mauch \& Dixon, 2012). Oscillator models of musical meter (Large \& Palmer, 2002; Large, 2008) derive metrical accent and stability from stimulus-driven resonances that are dependent upon event frequency and regularity, and most EEG and MEG studies of rhythm perception presume that salient musical events are more likely to occur on the beat (Brochard et al., 2003; Abecasis et al., 2005; Snyder \& Larger, 2005; Vuust et al., 2009). However, the shared presumption that onset frequency is correlated with metrical accent holds only contingently, that is, for the corpora of Western classical and popular music that were used in these studies, and for which these models were developed.

When one examines a musical corpus that is characterized by contrametric rhythms this presumption no longer holds. Contrametic, however, does not mean rhythmically unpredictable - for as our and Holzapfel's corpus studies have shown, in these repertoires note onset frequencies are stable and predictable at each position within the metric cycle. And it is precisely because there is a stable differentiation of the 
distribution of note onset frequencies relative to their metric framework that statistical learning processes can gain traction. Many musical genres, especially dance genres, are marked by characteristic rhythms which, by definition, share a common meter. Figure 6 lists several dance genres and their characteristic rhythms. If one were to examine a corpus of any of these genres, onsets in these positions would be statistically prominent, even though not all of them are metrically accented.

We would therefore argue that it is the recurrence and stability of rhythmic figures in a given style or repertoire (and the metrical predictability this recurrence entails) that is required for learning characteristic rhythm-meter relationships. While some styles may involve a strong correlation between note frequency and metrical accent, this is not required for the developing mental representations for meter in informal listening contexts (cf. Palmer \& Krumhansl quote above). As Large, Herrera \& Velasco (2015) have shown, cyclically recurring rhythms, even if they do not contain explicit beat-level periodicities, can still give rise to a sense of beat. To this we would add that situated encounters with characteristic rhythmic patterns can engender not only a sense of beat, but a sense of the higher and lower levels of metrical organization as well.

A listener's metrical knowledge comes from hearing rhythms and melodies in their normative, real-world situations (Keller 1999). In those contexts, performance timing information supplements the learning of rhythmic patterns, as we have suggested above. Moreover, we are able to orient characteristic usul or hook rhythms - the rhythmic layers that have the greatest influence on event frequencies within the measurerelative to other parts of the musical texture that project metrically unambiguous accompaniments (e.g., the Jembe2 part in Fig. 4). Once the relation of the hook to the basic meter has been grasped in the context of the full ensemble, one can "fill in" missing metrical information when one encounters it in isolation. Indeed, one may learn to associate particular timbres, frequency ranges, and articulations with various rhythmic and metric cues: the sound of the dundun is indicative of the hook part, and signifies that it is likely to mark an alternation of "onbeat" and "offbeat" locations, for example. As our Malian percussion pieces typically accompany dancers in social settings, there is also a rich visual and kinesthetic context in which these rhythms are experienced. The dancers' movements may be observed, or better yet, one might learn to dance, and thus know how to move with the music, whether or not one is actually dancing (Agawu 1995).

We therefore posit that while the frequency of onset occurrence of events doubtless plays a role in our acquisition of rhythmic and metric knowledge, those frequencies occur in holistic contexts that include timing, timbre and other auditory, visual, and sensorimotor channels of perception. Combinations of these cues forge associations between statistically common rhythms and their characteristic metrical orientations. In so far as the rhythms in a corpus have a stable and distinctive set of features that afford a clear affiliation with a particular meter, their statistical attributes may serve as cues for the appropriate metrical templates. While our Malian corpus is illustrative, it is not that different from most other corpuses of music marked by recurring characteristic rhythms (e.g., a "Mazurka" corpus or a "Reggae" corpus).

The study of African rhythm shows that the perceptual and cognitive relationships between rhythmic patterns and their interpretive metric frameworks are more complex and the potential for their independence is larger than has been assumed. It is also a reminder to psychological researchers that the behaviors we observe, and the models we create to explain them, are both often contingent facts of particular cultures, and that

(a) Mazurka

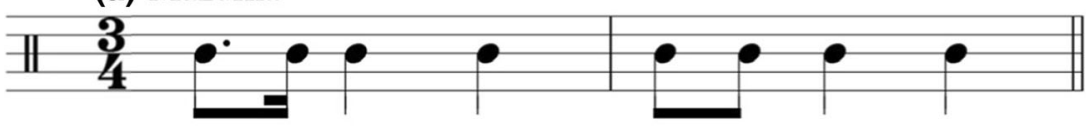

(b) Merengue

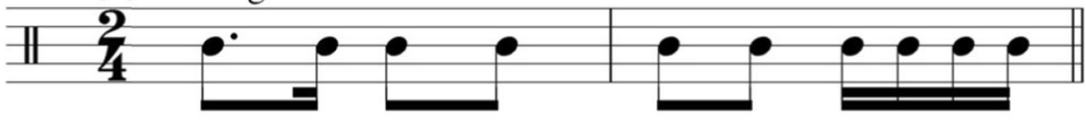

(c) Siciliana

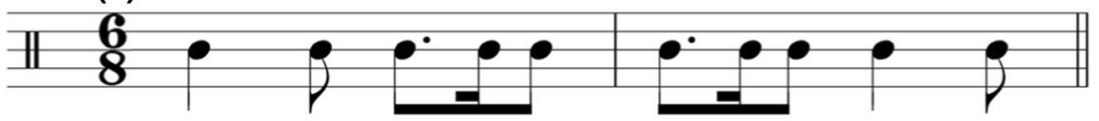

(d) Habanera

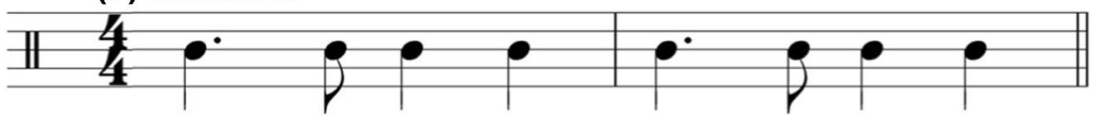

Fig. 6 Characteristic rhythms of several dance genres: a Mazurka, b Merengue, c Siciliana, d Habanera 
cross-cultural research can usefully inform our psychological theories in important ways.

\section{References}

Abecasis, D., Brochard, R., Granot, R., \& Drake, C. (2005). Differential brain response to metrical accents in isochronous auditory sequences. Music Perception, 22(3), 549-562.

Agawu, K. (1995). African rhythm: A northern Ewe perspective. Cambridge: Cambridge University Press.

Agawu, K. (2006). Structural analysis or cultural analysis? Competing perspectives on the 'standard pattern' of West African rhythm. Journal of the American Musicological Society, 59(1), 1-46.

Anku, W. (2000). Circles and time: A theory of structural organization of rhythm in African music. Music Theory Online 6(1), http://www. mtosmt.org/issues/mto.00.6.1/mto.00.6.1.anku.html

Arom, S. (1991). African Polyphony and Polyrhythm: Musical structure and methodology. Cambridge: Cambridge University Press.

Brochard, R., Abecasis, D., Potter, D., Ragot, R., \& Drake, C. (2003). The "ticktock" of our internal clock: Direct brain evidence of subjective accents in isochronous sequences. Psychological Science, 14(4), $362-366$.

Burns, J. (2010). Rhythmic archetypes in instrumental music from Africa and the diaspora. Music Theory Online 16(4), http:/www.mtosmt. org/issues/mto.10.16.4/mto.10.16.4.burns.html

Chor, I. (2010). Cognitive frameworks for the production of musical rhythm. Ph.D. Thesis, Northwestern University.

Ellis, D. (2007). Beat tracking by dynamic programming. Journal of New Music Research, 36(1), 51-60.

Holzapfel, A. (2015). Relation between surface rhythm and rhythmic modes in Turkish makam music. Journal of New Music Research, 44(1), 25-38.

Huron, D., \& Ommen, A. (2006). An empirical study of syncopation in American popular music, 1890-1939. Music Theory Spectrum, 28(2), 211-231.

Jehan, T. (2005). Downbeat prediction by listening and learning. 2005 I.E. Workshop on Applications of Signal Processing to Audio and Acoustics, New Paltz, NY.

Keller, P. (1999). Attending in complex musical interactions: The adaptive dual role of meter. Australian Journal of Psychology, 51(3), $166-175$.

Kolinski, M. (1973). A cross-cultural approach to metro-rhythmic patterns. Ethnomusicology, 17(3), 494-506.

Kubik, G. (1988). Einige Grundbegriffe und -Konzepte der afrikanischen Musikforschung. In G. Kubik (Ed.), Zum Verstehen afrikanischer Musik (pp. 52-113). Leipzig: Reclam.

Large, E. (2008). Resonating to musical rhythm: Theory and experiment. In S. Grondin (Ed.), The Psychology of Time (pp. 189-232). West Yorkshire: Emerald.

Large, E. W., Herrera, J. A., \& Velasco, M. J. (2015). Neural networks for beat perception in musical rhythm. Frontiers in Systems Neuroscience, 9, 159. doi:10.3389/fnsys.2015.00159
Large, E. W., \& Palmer, C. (2002). Perceiving temporal regularity in music. Cognitive Science, 26, 1-37.

Lerdahl, F., \& Jackendoff, R. (1983). A generative theory of tonal music. Cambridge: MIT Press.

Locke, D. (1982). Principles of offbeat timing and cross-rhythm in Southern Eve dance drumming. Ethnomusicology, 26(2), 217-246.

Locke, D. (1992). Kpegisu: A war drum of the Ewe. Tempe: White Cliffs Media.

Locke, D. (1998). Drum Gahu. Tempe: White Cliffs Media.

Locke, D. (2010). Yewevu in the metric matrix. Music Theory Online 16(4), http://www.mtosmt.org/issues/mto.10.16.4/mto.10.16.4. locke.html

Longuet-Higgins, H. C., \& Lee, C. S. (1982). The perception of musical rhythms. Perception, 11, 115-128.

London, J. (2012). Hearing in time (2nd ed.). New York: Oxford University Press.

Mauch, M., \& Dixon, S. (2012). A corpus based study of rhythm patterns. Proceedings of the 13th International Society for Music Information Retrieval Conference (ISMIR 2012) http://www.ismir2012.ismir.net/ event/papers/163_ISMIR_2012.pdf

Nzewi, M. E. (1997). African music: Theoretical content and creative continuum. The culture-exponent's definitions. Oldershausen: Institut für Didaktik populärer Musik.

Palmer, C., \& Krumhansl, C. A. (1990). Mental representations for musical meter. Journal of Experimental Psychology. Human Perception and Performance, 16(4), 728-741.

Polak, R. (2007). Performing audience: On the social constitution of focused interaction at celebrations in Mali. Anthropos, 102(1), 3-18.

Polak, R. (2010). Rhythmic feel as meter. Non-isochronous beat subdivision in jembe music from Mali. Music Theory Online 16(4), http:/ www.mtosmt.org/issues/mto.10.16.4/mto.10.16.4.polak.html

Polak, R. (2012). Urban drumming: Traditional celebration music in a West African city (Bamako). In E. Charry (Ed.), Hip Hop Africa: New African Music in a Globalizing World (pp. 261-281). Bloomington: Indiana University Press.

Sadakata, M., Desain, P., \& Honing, H. (2006). The Bayesian way to relate rhythm perception and production. Music Perception, 23(3), 269-286.

Snyder, J. S., \& Large, E. W. (2005). Gamma-band activity reflects the metric structure of rhythmic tone sequences. Cognitive Brain Research, 24(1), 117-126.

Stover, C. (2012). Review of The clave matrix: Afro-Cuban rhythm: Its principles and African origins by David Peñalosa. Latin American Music Review/Revista de Musica Latinoamericana, 33(1), 131-140.

Temperley, D. (2010). Modeling common-practice rhythm. Music Perception, 27(5), 355-376.

Tomic, S. T., \& Janata, P. (2008). Beyond the beat: Modeling metric structure in music and performance. Journal of the Acoustical Society of America, 124(6), 4024-4041.

Vuust, P., Ostergaard, L., Pallesen, K. J., Bailey, C., \& Roepstorff, A. (2009). Predictive coding of music-brain responses to rhythmic incongruity. Cortex, 45(1), 80-92. 